The United Nations

A Handbook on the New World Organisation. By Louis Dolivet. Pp. 144. (London: Phœnix House, Ltd., 1946.) 6s. net.

T is probably true to say that the prestige of the 1 United Nations Organisation has fallen as much in twelve months as that of the League of Nations fell in as many years. Disillusionment and bewilderment are as widespread as the realization that, for all such disappointment, the diagnosis of the founders of the Organisation remains correct. It is still true that Western civilization cannot indefinitely sustain the strain imposed upon it by the conflicting interests of the Great Powers.

If, however, this situation is to be retrieved and the United Nations Organisation is to succeed in its objectives, it must have the firm support of individual men and women throughout the world. That support must be based on clear understanding of the ramifications of the Organisation, the diversity of its problems and the mechanics of its operations. Mr. Dolivet's handbook is an objective contribution to that end. It is not a commentary, but a conscientious and workman-like attempt to give a factual picture of the actual structure and purposes of the Organisation. The book is readable, and although in some respects incomplete, being free from any attempt to record achievements or current controversies, it should assist the ordinary citizen to arrive at some independent judgment for himself. The appendixes include the Charter of the United Nations, the Statute of the International Court of Justice, and the names of representatives on the Security Council, the Military Staff Committee, the Atomic Energy Commission, and the delegates to the Economic and Social Council and to the First Assembly. If to future editions there could be added similar factual presentations of the relations with, and functions of, the Educational, Scientific and Cultural Organisation, the Food and Agricultural Organisation, and the like, which are in this edition rather summarily discussed, and of the trusteeship developments, it could well become a reference book that the ordinary citizen would be glad to have at hand.

R. B.

\section{Les Liquides Dispersifs et leurs Applications}

Par Dr. G. Ahier. Pp. 88., (Paris : Jouve et Cie., 1940.)

o WING to war conditions, this interesting monograph has only recently become available in Great Britain. It forms a useful summary of a great deal of work on the applications of liquids of high dispersivity, especially to the construction of Christiansen filters (C.R. Acad. Sci., Paris, 202, 1775 (1936); 205, 37 (1937); 206, 203 (1938)).

Christiansen filters consist essentially of a powdered solid immersed in a liquid of similar refractive index but different dispersivity. For one wave-length, the refractive indices are equal; the mixture is then homogeneous and transparent to this wave-length, while all other wave-lengths are scattered. The literature records the use of a number of such filters. Dr. Ahier's book discusses the theory of these filters, and derives formulæ which may assist in their construction. He also describes fully a series of liquids and solids with which he assembled filters which selected narrow bands of wave-lengths, from the visible region down to $1850 \mathrm{~A}$. Careful manipulation renders it possible to isolate bands, which, in some cases, were only $3 \mathrm{~A}$. wide. The merits and defects of Christiansen filters are compared with those of coloured filters and monochromators. In general, Christiansen filters are cheaper, more easily made, and more satisfactory from the point of view of both selectivity and optical density.

Dr. Ahier's book should be useful to workers requiring light filters, partly as a practical handbook, and partly as a review of the subject, including the infra-red region.

G. J. MrNKOFF

\section{Chemical Thermodynamics}

By Dr. J. A. V. Butler. Fourth edition. Pp. xvi +570. (London: Macmillan and Co., Ltd., 1946.) 12s. 6d.

IN this book, the author has brought together in 1 one volume the two parts of his introduction to thermodynamies, which were formerly published separately. The first part gives a straightforward and elementary account of the first and second laws, and their application, with the emphasis towards electrochemistry. The second part, which is considerably more advanced, deals with the more important thermodynamic functions and the third law, and their applications. This part has been revised and brought up to date, and a good deal of new material added. The revision could, with advantage, have been extended to Part 1; even the youngest student may, in this atomic age, raise his eyebrows at the statement on p. 4 that "According to some modern physical theories, matter and energy are interconvertible. If this were substantiated, the Conservation of Energy would be replaced by a wider principle of the Conservation of Mass Energy." There might also, with advantage, have been a closer synthesis of the text of the two parts.

The book contains a good deal more than its title implies, and discussions of detailed mechanisms are frequently included. This adds considerably to the value of the book, since it gets down to fundamentals. In particular, the author writes interestingly and well on the subjects in which he has made original contributions, such as the kinetic theory of the electrode processes, or the mechanism of over-potential. There is a large number of well-selected examples, many of which are worked out; and a short but very clear account of the application of statistical methods to the determination of thermodynamic functions, by the late Dr. W. J. C. Orr, has been added as an appendix. The book should continue to prove a useful and stimulating introduction to the subject.

F. P. BOWDEN

\section{General Mathematics}

By Clement V. Durell. Vol. 1. Pp. xv $+312+x l v i i$. Vol. 2. Pp. xxxi+324+xl. (London: G. Bell and Sons, Ltd., 1946.) 5s. without Answers; 5s. $6 d$. with Answers, each Vol.

A $\mathrm{S}$ Mr. Durell rightly says in his preface, "eleA mentary mathematics should be treated as a single subject". The course embodies many modern ideas of teaching designed to meet the expanding and changing needs of post-war secondary schools. It deals with arithmetic, algebra, geometry and trig. onometry, and covers all the requirements laid down in the current syllabuses of the various School Certificate examining authorities.

Each book contains many exercises which are classified into two main groups : a first course, and a parallel course. The first is intended for all pupils, while the second provides extra practice. Useful test papers and revision exercises are supplied, together with answers to all exercises. 